\title{
Anaology of Jute Fiber with Mud Crab Shell and Mussels Shell Powder Filler Reinforced Isopthalic Polyester Resin Based Composites
}

\author{
A.K. Arun Raja, K. Arun Vasantha Geethan, P. Sabarish Kumar, P. Priyan, P. Shabin Raj
}

\begin{abstract}
Jute fibers are totally biodegradable and recyclable substances, i.e., environmentally friendly substances. The contemporary annual global production of jute fiber is ready 3.2 million tons and used for diverse packages. Various research is being accomplished to discover a suitable substitute for the nonbio degradable plastic strengthened composites, which has a negative effect at the environment. The mercerization technique is executed the use of $8 \%$ of sodium in water to form the sodium hydroxide (NaOH). The property of the fabric is similarly promoted with the aid of adding mud crab shell powder and mussels shell powder all through the hand moulding process. The composite fabric is evolved with the assist of isophthalic polyester resin with $2 \%$ of accelerator and hardener used at the side of it. Experiments are executed as according to ASTM requirements to discover the mechanical properties. In addition to mechanical properties HDT(Heat Deflection Test) and rate of burning test are done. With help of the studies and study,Jute fabric mat can be used as an alternate for plastic components (non bio degradable).
\end{abstract}

Keywords: Jute, Isophthalic, hand moulding process, Mercerization, Reinforcement.

\section{INTRODUCTION}

The nature of natural fiber such as it is less weight, reuseable, eco-friendly and offers ahighoverall performance in relation to its mechanical properties makes this material an best alternative for the presently used components in the manufacture of automobile components[1].More than 100 years natural fibers are used in the world.As the automobile market and its supportive industries were increses massive quantity of natural composite material fed on as more automobile components. However at the given up of the product life; products begin every other life cycle, both by recycling or disposal in a variety of manners[2].

Manuscript received on June 16, 2021.

Revised Manuscript received on June 22, 2021.

Manuscript published on June 30, 2021.

* Correspondence Author

Mr. A. K. Arun Raja, Assistant Professor, Department of Mechanical Engineering, St. Joseph's Institute of Technology, OMR, Chennai (Tamil Nadu), India.

Dr. K. Arun Vasantha Geethan, Professor and Head, Department of Mechanical Engineering, St. Joseph"s Institute of Technology, OMR, Chennai, Chennai (Tamil Nadu),India.

Mr. P Sabarish Kumar, Assistant Professor, Department of Mechanical Engineering, St. Joseph's Institute of Technology, OMR, Chennai (Tamil Nadu),India.

Mr. P. Priyan*,Student, Department of Mechanical Engineering, St. Joseph's Institute of Technology, OMR, Chennai (Tamil Nadu), India.

Mr.P. Shabin Raj, Student, Department of Mechanical Engineering, St. Joseph's Institute of Technology, OMR, Chennai (Tamil Nadu),India.

(C) The Authors. Published by Blue Eyes Intelligence Engineering and Sciences Publication (BEIESP). This is an open access article under the CC BY-NC-ND license (http://creativecommons.org/licenses/by-nc-nd/4.0/)
The developments in the direction of utilization of natural fibers in the automobile zone started out in the 1990s in Europe and reached North America some years later.

The demand for strengthened plastics in the United States is projected to grow $2.5 \%$ yearly to over fourbillion (1.81 billion $\mathrm{kg}$ ) pounds in 2007, valued at US\$6.5 billion.1,6,7 This willcreate a market for 2.8 billion (1.27 billion $\mathrm{kg}$ ) pounds of resin and 1.3 billion( 0.59 billion $\mathrm{kg}$ ) pounds of reinforcements. The automobile and constructionindustries will continue to be the main markets for reinforcedplastics, together accounting for $63 \%$ of the whole in 2007[3]. Jute is the common natural fiber which has high productivity in india. Jute fiber reinforced polymer composites have proved to be higher then few structural meaturial previously made up of wood and steel. Most types of jute fibers are light brown, but some off-white varieties are also obtained. Since it is sturdy and flexible, the fiber is generally easy to work with and is long and gleaming in its raw state. [4].

\section{FABRICATION}

\section{A. Materials used}

The Jute fabric is ordered and bought from the Anakaputhur Jute Weavers Association. The Isophthalic polyester resin, and corresponding hardener (Methyl Ethyl Ketone Peroxide) and accelerator (Cobalt Octoate) supplied with the aid of Sakthi fiber glass, which have been used to prepare the composites. The Jute fabric is bow obtained in mat form.

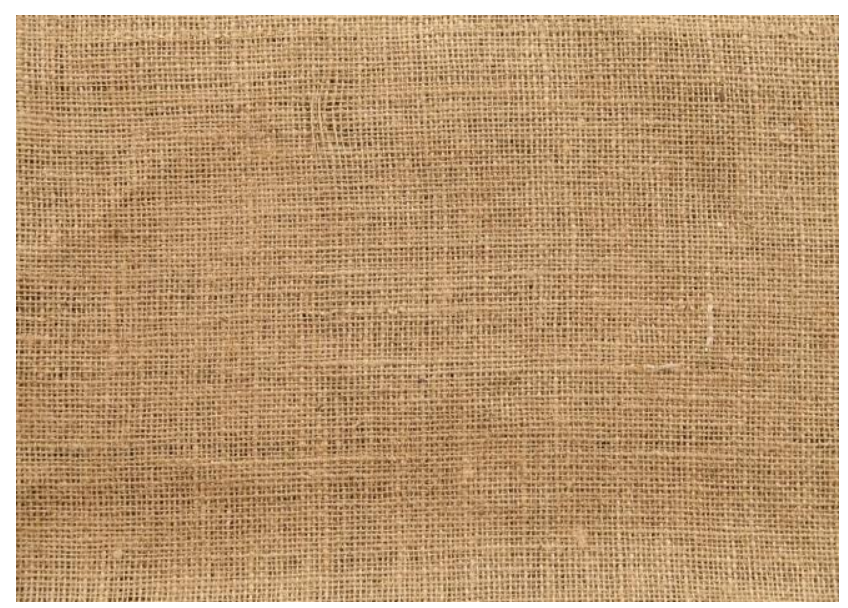

Fig. 1. Jute Fabric

Published By:

Blue Eyes Intelligence Engineering and Sciences Publication

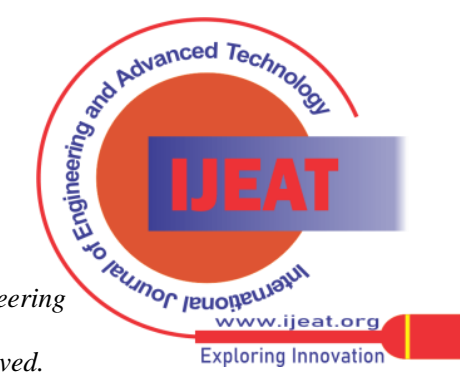




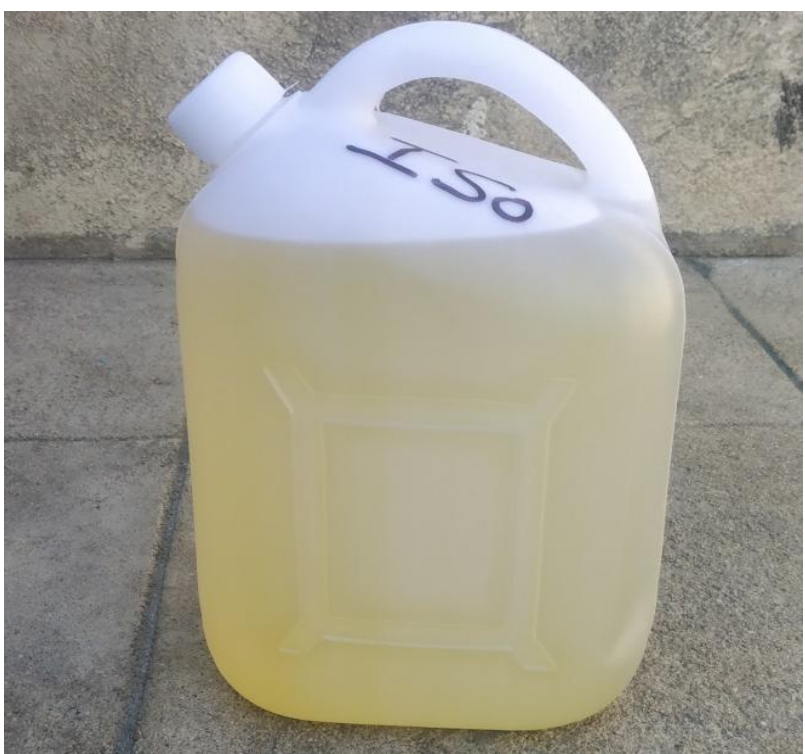

Fig. 2.Isopthalic Polyester Resin

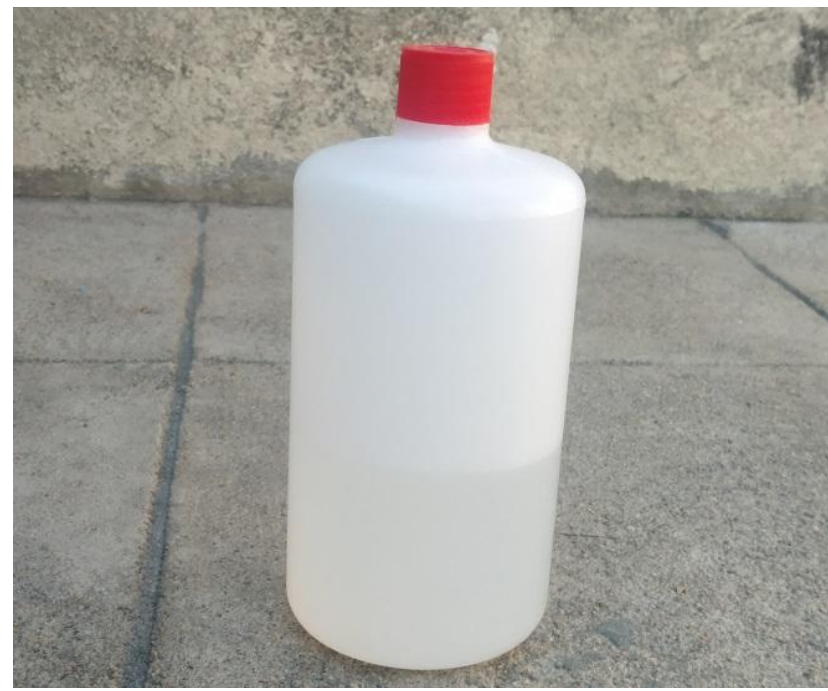

Fig. 3.Methyl Ethyl Ketone Peroxide

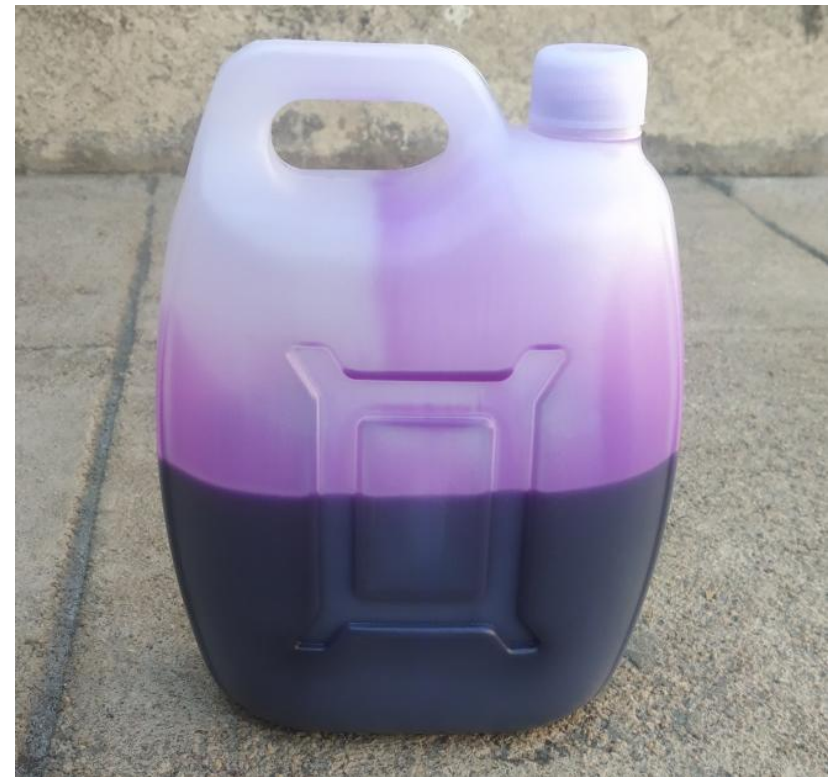

Fig. 4.Cobalt Octoate

In order to expand the properties of the Jute fabrics, it is chemically treated with water solutioncontaining 8\% sodium salts $(\mathrm{NaOH})$ dissolved in it, this process is called as mercerization process.

fiber $-\mathrm{OH}+\mathrm{NaOH} \rightarrow$ fiber $-\mathrm{O}-\mathrm{Na}+\mathrm{H}_{2} \mathrm{O}$

Jute fabric is soaked in $8 \%$ of sodium hydroxide $(\mathrm{NaOH})$ solution for 11 hour. Dried at room

Temperature (28-32) for 48 hour. Then heat dried for few minutes. This makes the Hydrophilic nature of the mat into Hydrophobic nature. Then the Jute fabrics where cut into uniform shape.

\section{COMPOSITE FABRICATION}

The isophthalic polyester resin and its corresponding accelerator and hardener were mixed as $2 \%$ of resin. Then add the filler (A-mud crab shell powder , B-mussels shell powder) as $5 \%$ according to the weight. In order to enhance elevated interior bonding and to expand crosslink density of the composites, the fillers are used in the isophthalic resin solution[5]. Take $750 \mathrm{ml}$ of resin in a beaker which is added with the hardener and accelerator and then apply the solution layer by layer in the jute faibre. The process is carried out by hand mouldingprocess[6] and the outcome of the composite is shown in the Fig.5 and Fig.6.

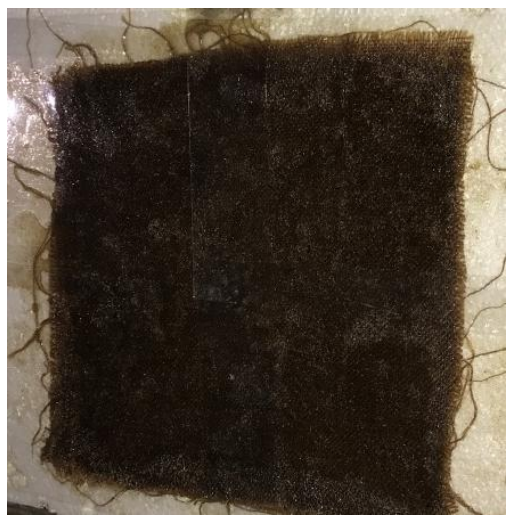

Fig. 5. Jute fiber with mud crab shell powder

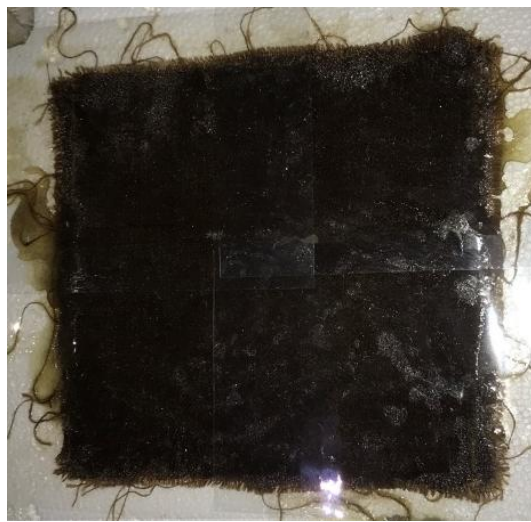

Fig. 6. Jute fiber with mussels shell powder

\section{METHODOLGY}

Various mechanical test is carried out in order to recognize and examine the mechanical property of the isophthalic based Jute.All the mechanical test is carried out according to the ASTM D standards. The following are mechanical test carried out:

Published By:

Blue Eyes Intelligence Engineering and Sciences Publication

(c) Copyright: All rights reserved.

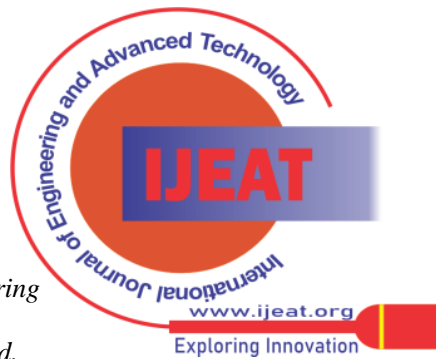




\section{A. Tensile Test}

Tensile testing, additionally known as tension testing, is a indispensable materials science and engineering check in which a sample is subjected to a managed tension until failure. Properties that are directly measured by a tensile test are last tensile strength, breaking strength, maximum elongation and reduction in area. From these measurements the following properties can additionally be determined: Young's modulus, Poisson's ratio, yield strength, and strainhardening characteristics. Uniaxial tensile testing is the most typically used for obtaining the mechanical characteristics of isotropic materials. Five samples were tested in each set and average is tabulated for each specimen.[7]

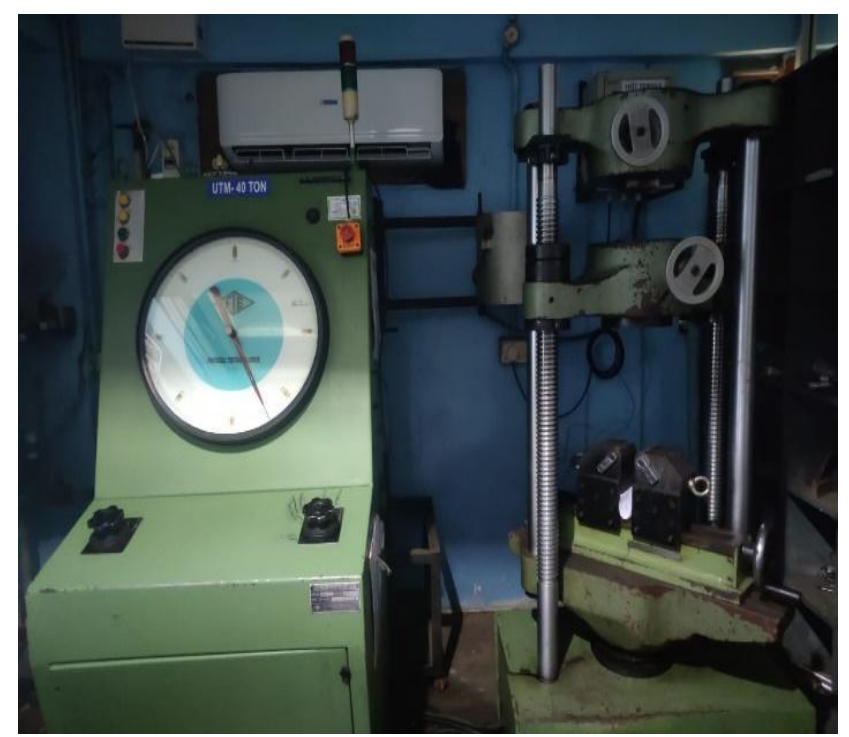

Fig. 7.Universal Testing Machine (UTM)

Tensile assessments are usually conducted on electromechanical or Universal Testing Machine (UTM) at a crosshead velocity of $50 \mathrm{~mm} / \mathrm{min}$ and a gauge length of $50 \mathrm{~mm}$. The Tensile test used to be performed in accordance to the ASTM D 638 standards. The test specimens used were rectangular in form with dimensions $120 \mathrm{~mm}$ x $12.5 \mathrm{~mm}$ x $3 \mathrm{~mm}$. Five samples have been tested in every set and the average. Fig.7 represents the anatomy of the Universal Testing Machine (UTM).

\section{B. Flexural Test}

The most common motive of a flexure test is to measure flexural power andflexural

modulus.Flexural strength is described as the most stress at the outermost fiber on both the compression or tension facet of the specimen.The material is laid horizontally over two factors of contact (lower support span) and then a pressure is applied to the top of the material through either one or two points of contact (upper loading span) till the sample fails. The most recorded force is the flexural strength of that sample. The flexural modulus of the fabric increases with increase in fiber loading[8].

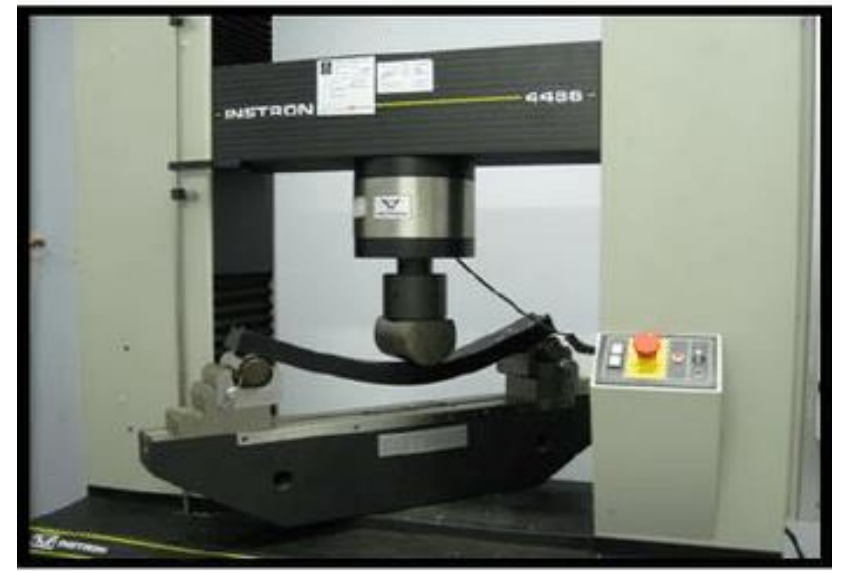

Fig. 8. 3-point Flexural Testing Meachine

Flexural properties of the composites have been measured by using a three-point loading device as per ASTM D 790 the usage of a universal testing machine with rectangular samples of dimension $120 \mathrm{~mm} \mathrm{x} 12.5 \mathrm{~mm}$ x $3 \mathrm{~mm}$.

A minimum of 5 samples had been examined in each case and average of these results are tabulated for future calculation.

\section{Compression Test}

A compression test is any test in which a material experiences opposing forces that push inward upon the specimen from opposite sides or is otherwise compressed, "squashed", crushed, or flattened. The test sample is usually positioned in between two plates that

the utilized load throughout the whole floor area of two opposite faces of the test pattern and then the plates are pushed collectively by

means of a universal test machine causing the sample to flatten[9]. Both the samples are taken as the measurement of $120 \mathrm{~mm}$ x $12.5 \mathrm{~mm}$ x $3 \mathrm{~mm}$ thickness. The compression test is also carried out in the universal testing machine. The samples are loaded in the machine and results are tabulated.

\section{Impact Test}

Impact tests are used in analyzing the toughness of material. A material's toughness is a element of its capacity to soak up energy all through plastic deformation.Charpy impact test, additionally recog-nized as the Charpy V-notch test, is a standardized excessive strainrate test which determines the quantity of energy absorbed through a material for the duration of fracture. Absorbed energy is a measure of the material's notch toughness[10].

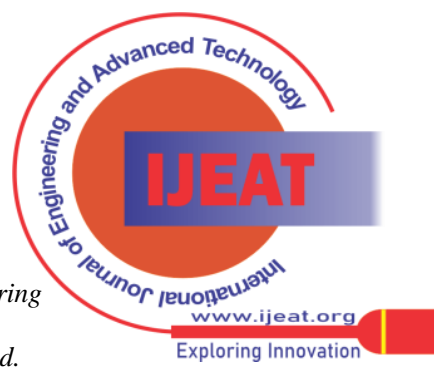




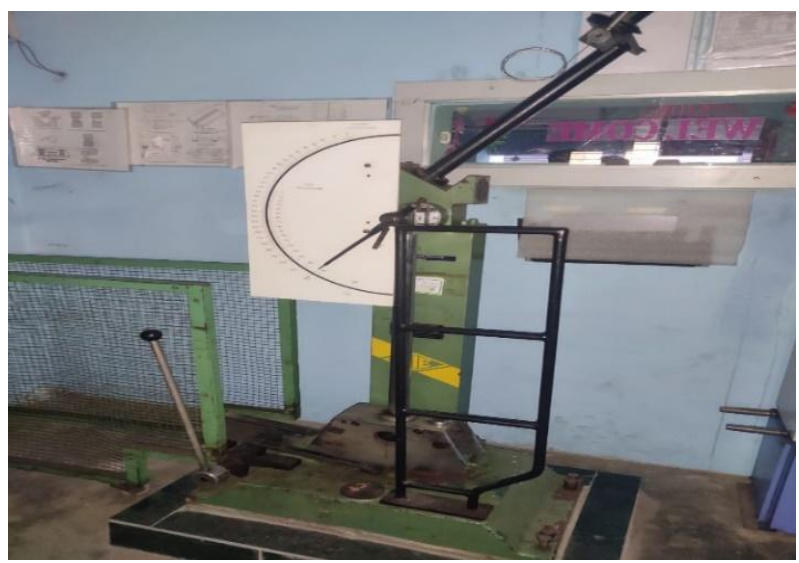

Fig. 9.ImpactTestngMeachine

The Fig.9 shows the impact testing used for the experimental work. For each case, a sample of 5 is taken and tested and the average value is tabulated.

\section{E. HDT( Heat Deflection Temperature)}

The heat deflection temperature is the temperature at which a polymer plastic sample deforms underneath a specifies load. The property of a given plastic material is utilized in many components og production design, engineering and manufacture of merchandise using thermoplastic components[11].

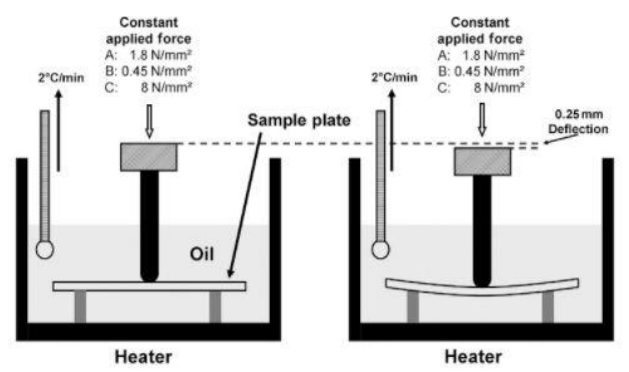

Fig. 10. HDT Test

.The heat distortion temperature is determined by the following test procedure outlined in ASTM D648.

\section{F.Rate of Burning Test}

In this test, the end result is the measurement of a material's flammability and rate of combustibility of that material. Initially the test specimen is supported horizontally at one end, and the free end is uncovered to a gas flame for 30 seconds. After elimination of the flame, the test specimen is discovered for time and extent of burning.

\section{RESULT AND DISSUCION}

The results are received from the common value recived from the following tests mentioned. Five sample were tested in it for each test. The mean value is calculated and tabulated.

The sample is give tag as A and B

A- Jute fiber with mud crab shell powder

B- Jute fiber with mussels shell powder

Similarly, in graphical representation Jute fabric with mud crab shell powder composite is indicated using blue color and Jute fabric with mussels shell powder composite is indicated using red color.

\section{A. Mechanical Property}

The main mechanical properties such as Tensile, Flexural, Compression and Impact were tabulated below. In this specimen the tensile strength of sample $A$ is grater than the sample $\mathrm{B}$. when compare to other test research flexural strength of the sample B is grater thn the sample A. In compression strength also the value od sample $\mathrm{B}$ is greater than the sample $B$. At laste the impact strength also the strength of Sample B is gtater than the sample A.

Table.1 . Mechanical Property Readings

\begin{tabular}{ccccc}
\hline Speciman & Tensile & Flexural & Compression & Impact \\
\hline Unit & MPa & MPa & MPa & MPa \\
A & 24.58 & 41.33 & 47.8 & 20 \\
& 22.34 & 43.36 & 66.1 & 40 \\
\hline
\end{tabular}

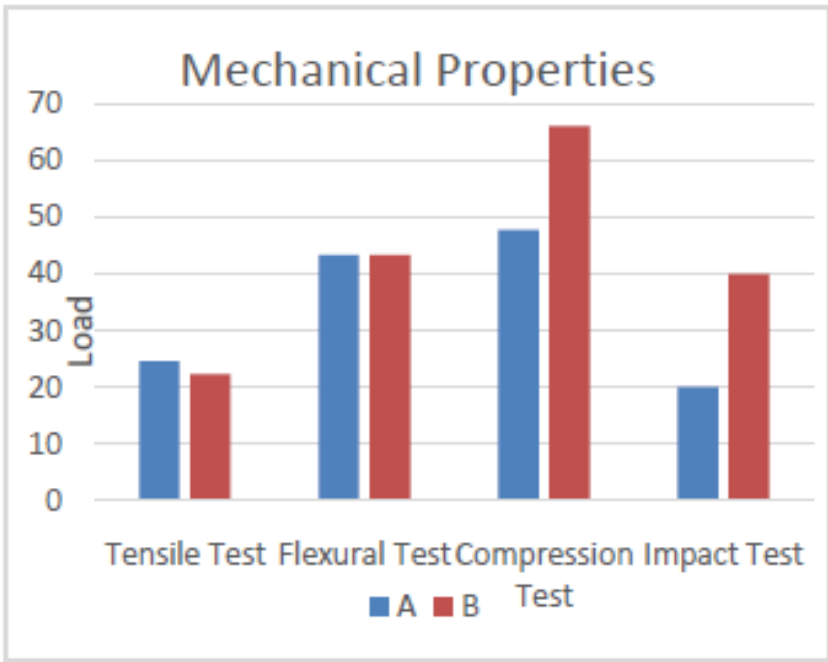

Fig. 11. Mechanical Properties

\section{B. Heat Deflection Temperature (HDT)}

HDT test is carried out in ASTM D790. Test parameter is HDT: $1.82 \mathrm{MPa}$. In HDT test the sanple $\mathrm{B}$ is grater than the sample A.

Table. 2. HDT Test

\begin{tabular}{|c|c|c|c|c|}
\hline S.No & Sample & Unit & $\begin{array}{c}\text { Test } \\
\text { method }\end{array}$ & $\begin{array}{c}\text { Test } \\
\text { result }\end{array}$ \\
\hline 1 & A & ${ }^{\circ} \mathrm{C}$ & $\begin{array}{c}\text { ASTM } \\
\text { D648 }\end{array}$ & 59.7 \\
\hline 2 & $\mathrm{~B}$ & ${ }^{\circ} \mathrm{C}$ & $\begin{array}{c}\text { ASTM } \\
\text { D648 }\end{array}$ & 60.9 \\
\hline
\end{tabular}

Published By:

Blue Eyes Intelligence Engineering and Sciences Publication

(C) Copyright: All rights reserved.

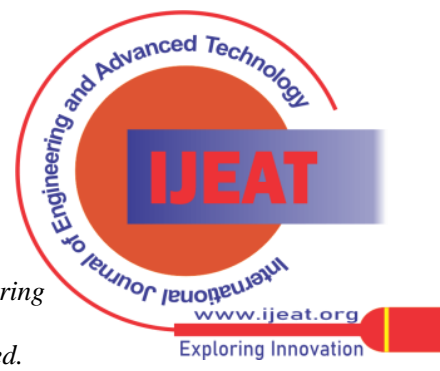




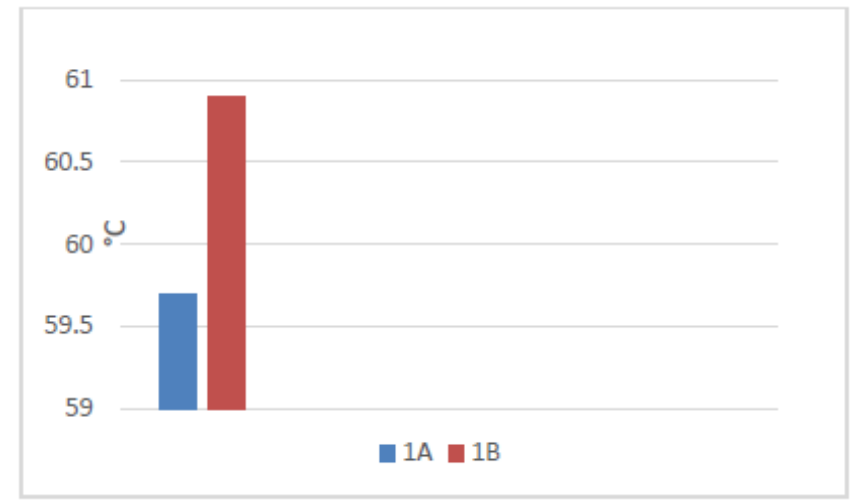

Fig. 12.Comparation of HDT test

\section{Rate of Burning}

In terms of Rate of burning it is high in sample B followed by sample A by small margin.

Table.3.Rate of burning

\begin{tabular}{|c|c|}
\hline Speciman & $\begin{array}{c}\text { Rate of Burning } \\
\text { (mm/mins) }\end{array}$ \\
\hline A & 12.44 \\
\hline B & 14.43 \\
\hline
\end{tabular}

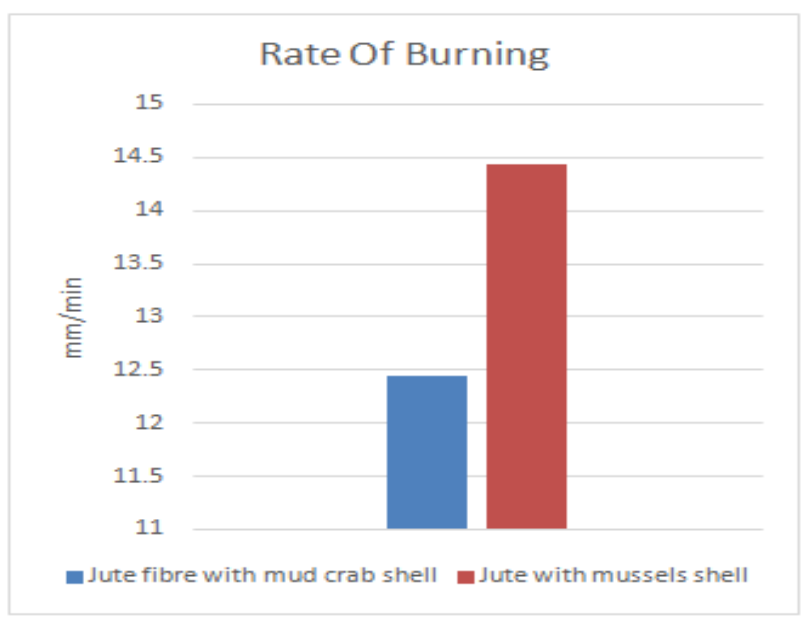

Fig. 13.Comparisonof Rate of Burning

\section{CONCLUSION}

In technology ofrisky environment utilization of natural fiber as reinforcement has been demonstrated as environment friendly choice to usual artificial fibers. Extensive study has been made to discover the mechanical strength of Jute Fiber with mud crab and mussels shell powder bolstered composite, with an result proving the following Inference

- Mechanical properties of Jute Fabric composite are nearly at par with plastic fabric in each aspect, thinking environmental component it about the is wise to use natural basednatural Jute fabric composite than the plastic composite.

- The Jute Fabric composite with mud crab and mussels shell powder produces nearly the equal charge of burning, so they can be used in the area of Thermal application
- $\quad$ Further lookup on

Jute fabric mat

is recommended, examined with two one of a kind filler material and resins in order to extend the mechanical property and structural integrity Bamboo fabric composite

\section{REFERENCE}

1. Muhammad Noryani, SalitMohdSapuan, Mohammad TahaMastura, MohdYusoffMohZuhri, Edi SyamsZainudin, "Material selection of natural fiber using a stepwise regression model with error analysis".

2. Favis M. AL-Oqla, Mohd S. Salit, "Natural fiber composites".

3. M S Huda .L T Drzal, "Natural-fiber composites in the automotive sector".

4. NitheshNaik, B. Shivamurthy, B.H.S. Thimappa, AmoghGovil, Pranshul Gupta, RiteshPatra, "Enhancing the mechanical properties of jute fiber reinforced greencomposites varying cashew nut shell liquid composition and usingmercerizing process."

5. MojtabaTabatabaeian, AlirezaKhaloo, HoomanKhaloo, "An innovative high performance pervious concrete with polyesterand epoxy resins".

6. A. Hallonet, E. Ferrier, L. Michel, BrahimBenmokrane, "Durability and tensile characterization of wet lay-up flax/epoxycomposites used for external strengthening of RC structures".

7. Ramesh BabuAdusumalli, KarthikChenthanVenkateshan, ChandrakalaKunchu,Surya R. Vadlamani, "Tensile testing of single fiber".

8. PreetiRanjanPani, R.K.Nayak, B.C.Routara, P.C. Sekhar, "Flexura and Specific Wear Rate of Seawater Aged Bamboo, Juteand Glass Fiber Reinforced Polymer Hybrid Composites".

9. MortezaNejati, Marie Luise Texas Dambly, Martin O. Saar, "A methodology to determine the elastic properties of anisotropic rocks from a singleuniaxial compression test".

10. G. Simeoli, L. Sorrentinob, F. Touchard, D. Mellier, M. Oliviero, P. Russo, "Comparison of falling dart and Charpy impacts performances of compatibilized and not compatibilized polypropylene / woven glass fiberscomposites".

11. VahidDaghigh, Thomas E. Lacy Jr., Hamid Daghigh, Grace Gu, Kourosh T. Baghaei, Mark F. Horstemeyer, Charles U. Pittman Jr, "Heat deflection temperatures of bio-nano-composites using experimentsand machine learning predictions".

\section{AUTHORS PROFILE}

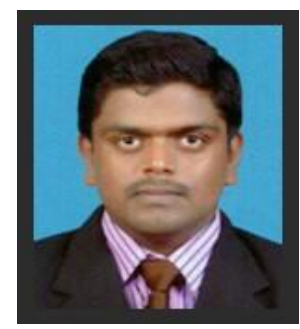

Mr. A. K. Arun Raja, is working as an Assistant Professor in Mechanical Engineering Department in St. Joseph's Institute of Technology, OMR, Chennai, Tamil Nadu, India. He has a work experience of 8 years as assistant professor. He is currently pursuing his Ph.D. from Sathyabama University, OMR, Chennai, Tamil Nadu, India, in the topic "Bio Composites". He has done a total of 12 publications including Scopus and sci indexed journals. He has guided number of college students in completing their project on natural reinforced composites.

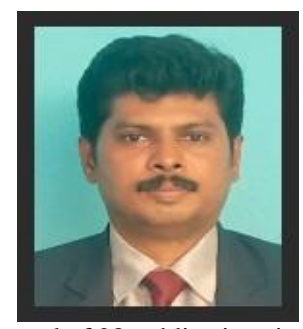

Dr. K. Arun Vasantha Geethan, is working as a Professor and the Head Of the Departmen of Mechanical Engineering in St. Joseph"s Institute of Technology, OMR, Chennai, Chennai, Tamil Nadu, India. He has a work experience of about 15 years in the field of teaching. He has done his Masters in Anna University, Chennai. He is also awarded with Doctor of Philosophy in "Reverse supply chain management" as area of research. He has a total of 28 publications including SCI and Scopus Indexed Journals.

Published By:

Blue Eyes Intelligence Engineering and Sciences Publication 


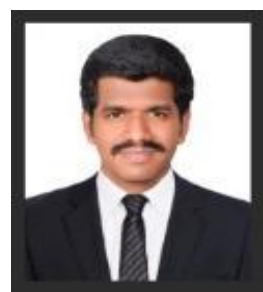

Mr. P Sabarish Kumar, is working as an Assistant Professor in Mechanical Engineering Department in St. Joseph's Institute of Technology, OMR, Chennai-600 118. He has a work experience of 6 years in the field of teaching. He is currently pursuing his Ph.D. from SRM university, Kattankulathur, Chennai, Tamil Nadu, India with "Heat exchangers" as research area. He has done a total of 13 publications including Scopus indexed journals.

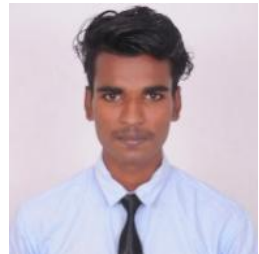

TVS Private Limited.

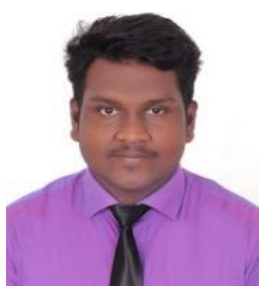

Mr. P Priyan, is a final year student pursuing his B. E. degree in mechanical engineering in St. Joseph's Institute of Technology, OMR, Chennai, Tamil Nadu, India. He also completed a project in Design and Fabrication of pot making mechanism. He has also attended a lot of workshops and inplant of his department core industries such as Industrial Automation conducted by AGIIT and

Mr. P Shabin Raj, is a final year student pursuing his B. E. degree in mechanical engineering in St. Joseph's Institute of Technology, OMR, Chennai, Tamil Nadu, India. He also completed a project in Design and Fabrication of pot making mechanism. He has also attended a lot of workshops and inplant of his department core industries.

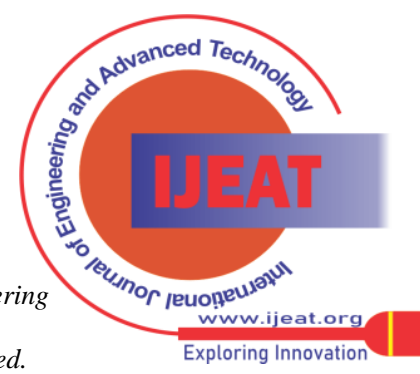

